\title{
Medical Education Department Roles and Initiatives towards Achieving APEX Agenda
}

\author{
Muhamad Saiful Bahri Yusoff, Ahmad Fuad Abdul Rahim, Rogayah Ja'afar \\ Medical Education Department, School of Medical Sciences, Universiti Sains Malaysia, Kubang Kerian, 16150 \\ Kota Bharu, Kelantan, Malaysia.
}

\section{ARTICLE INFO

$\begin{array}{ll}\text { Received } & : 03 / 04 / 2014 \\ \text { Accepted } & : 13 / 04 / 2014 \\ \text { Published } & : 01 / 06 / 2014\end{array}$

\section{KEYWORD}

APEX

Medical Education

(C) Medical Education Department, School of Medical Sciences, Universiti Sains Malaysia. All rights reserved.

CORRESPONDING AUTHOR: Muhamad Saiful Bahri Yusoff, Medical Education Department, School of Medical Sciences, Universiti Sains Malaysia, Kubang Kerian, 16150 Kota Bharu, Kelantan, Malaysia.

Email: msaiful_bahri@usm.my

Medical Education Department (MED) is a small department compared to other departments in the School of Medical Sciences, Universiti Sains Malaysia. This editorial describes the relevant roles and initiatives of MED towards achieving the 8 APEX (Accelerated Program for Excellence) transformation plans based on ERRC (Eliminate-Reduce-Raise-Create) grid (1):

1. Transforming nurturing (teaching) and learning

2. Transforming research and innovation

3. Transforming services and external activities

4. Transforming students and alumni

5. Transforming postgraduate studies

6. Transforming the concentration of talent

7. Transforming resources

8. Transforming supportive governance

\subsection{Nurturing (teaching) and learning}

\subsection{Faculty development}

The twelve roles of an educator that range from being a lesson planner, educational resource developer, assessor, facilitator for learning, information provider to being a role model to students require a substantial amount of preparation and commitment from the institution and individual educator (2). To ensure medical teachers are confident and competent to carry out all of these roles, they need to be prepared and trained (3). Therefore, faculty development plays a vital and integral role to develop capable and competent human resource for medical schools to nurture their students to become future good doctors $(3,4)$.

Faculty development in the medical education context is widely referred to as a structured program that is specifically planned and offered to medical teachers to develop their capability to 
become better and more efficient educators as well as to fulfill other aspects of the multifaceted academic roles which include conducting research, presenting research outcomes, writing publishable articles, contributing to administrative and managerial activities, etc (3$5)$. Indeed, it is seen as an essential method to enhance the vitality of an academician at either the medical school or institutional level (4). In a nutshell: "A comprehensive faculty development program is certainly not a part-time responsibility for one faculty member or administrator, nor it is a program that can be carried out exclusively with volunteer help (3)." It is carried out with serious intention, commitment, dedication and planning to ensure that it provides the utmost impact on the selfdevelopment of medical teachers to fulfill their roles and responsibilities as educators $(3,6)$ of students to become future competent doctors who will then serve society with the highest quality of patient care. So far, the department has conducted more than 200 faculty development activities since 1986 and more than 4,000 faculty members have attended the activities (3), and demand for such activities are increasing over the last three years.

\subsection{Facilitating student involvement in learning}

Another role of the MED is to plan and offer educational activities that facilitate student involvement in learning. Student involvement is referred to the amount (quality or/and quantity) of physical and psychological energy that the student devotes to the academic experience (7). Based on this definition, obviously a student who is highly involved is the one who devotes a substantial amount of energy to learning, spends much time on activities that facilitate learning, participates actively in extra-curricular activities, and interacts frequently with faculty members and other students. Conversely, a student who is uninvolved commonly spends less time learning, wastes much time on unbeneficial activities, do not participate in extracurricular activities, and has infrequent interactions with faculty members or other students. Therefore, to ensure medical students are involved in learning, they need to be prepared and trained to sustain their involvement to learning. Thus, student development activities to nurture and prepare the students for learning in medicine is a vital and integral component either at personal or professional levels $(8,9)$. One of indicators for effectiveness of any educational policy or practice is the capacity of that policy or practice to increase students' involvement in the learning process (7).

Examples of student development activities conducted by the department to facilitate student involvement in learning include the various study skills (10), examination skills (11), and PBL training workshops (12).

\subsection{Promoting scholarship of and scholarly teaching through the Online Peer-Reviewed Educational Material (OPREMA) system for Medical and Allied Health Profession}

Another role of the MED is to promote scholarship of and scholarly teaching among medical teachers. Its importance is becoming apparent nowadays (13). Scholarly teaching refers to how teachers utilize the literature to design their teaching, while scholarship of teaching refers to teachers doing research and contributing knowledge to the field $(13,14)$. A series of workshop on publishing teaching materials (14) were conducted for interested medical teachers who found them very useful in providing insight on ways to publish and disseminate teaching materials to the educational community.

In an effort to improve the quality of published teaching materials and to widen the readership of the published materials, the MED took an initiative to develop the Online Peer-Reviewed Educational Material (OPREMA) system to facilitate publication of teaching materials through a standard and rigorous peer-review process just like a journal publication. This publication model was developed based on the educational scholarship guide provided by the MedEdPORTAL (15). The OPREMA comprises of an editor-in-chief, editorial board members and reviewers from various medical backgrounds. The OPREMA is under development and expected to be fully operating by the middle of 2015. It is hoped that this new model of publication system is able to promote 
scholarship of and scholarly teaching among medical and allied health teachers in USM, nationally as well as around the globe. Apart from that, it is also expected to increase the visibility of Malaysian medical and allied health teachers in the international educational community.

\subsection{Research and innovation}

\subsection{Grants}

Based on the available data from Jan 2009 to June 2012, MED received 2 Incentive grants (RM 10,000), 9 short-term grants (total RM 203,338), 2 RU grants (total RM 298,675), 1 external grant (RM 120,000) and 3 APEX incentive grants (RM 76,140). The total amount of grants received by the department 3 years after the APEX status was RM 708,153. Prior to the APEX status (i.e. Jan 2005 to June 2008), the department received 1 incentive grant (RM 5,000), 1 short-term (RM 10,694), 1 external grant (RM 10,000) and 2 international grants (RM 273,000), totaling RM 298,694. These facts show a substantial increase in the number and amount of grants received by the MED after getting the APEX status. This indicates that the department is actively contributing to the APEX transformation agenda (1).

\subsection{Research publications}

Based on the available data from Jan 2009 to Dec 2012 (i.e. after the APEX status), there were 130 publications by the department members and 13 articles are in press for publication. The 130 publications comprised of 89 journal articles, 36 monographs, 3 chapters in textbooks and 2 abstracts published in journals either at international or national levels. Data from Jan 2005 to Dec 2012 (i.e. before the APEX status), showed 24 publications published by the department: all were journal articles at either international or national levels. This suggests a substantial increase of efforts by the department to disseminate knowledge through various forms of publications. The increase in publications also corresponded with the total amount of grants obtained. It is a positive and encouraging sign of the effort as well as initiative of MED towards achieving the APEX transformation agenda (1).

\subsection{Innovation}

The Post APEX era showed a list of innovations produced by the department; several of them having obtained intellectual property right (IPR). The following are the lists of innovations produced by the department from Jan 2009 to Dec 2012 and some of them are now indexed in PsycTEST Database published by American Psychologist Association (APA):

1. The Medical Student Stressor Questionnaire (MSSQ) (Indexed in PsycTEST)

2. The USM Emotional Intelligent Inventory (USMEQ-i) (Indexed in PsycTEST)

3. The USM Personality Inventory (USMaP-i) (Indexed in PsycTEST)

4. The Learning Approach Inventory (LA-i) (Indexed in PsycTEST)

5. The Adult Learning Inventory (AL-i) (Indexed in PsycTEST)

6. The Secondary School Stressor Questionnaire (3SQ) (Indexed in PsycTEST)

7. The Postgraduate Stressor Questionnaire (PSQ) (Indexed in PsycTEST)

8. The General Stressor Questionnaire (GSQ) (Indexed in PsycTEST)

9. The Discrepancy-Agreement Grade (DAG) $(16,17)$

10. The DEAL model of stress management (18)

11. The BigSib program (9)

12. MySTaR (My Self-Transformation and Reflection) (19)

Based on the latest usage report, the MSSQ was requested by 56 researchers, the USMEQ-i was requested by 43 researchers, the USMaP-i was requested by 15 researchers, the 3SQ was requested by 9 researchers and the GSQ was requested by 3 researchers. We believe that the usage numbers for these inventories are more that the reported figures. All inventories are currently made available free of charge.

\subsection{Education in Medicine Journal (EIMJ)}

The EIMJ is another MED landmark initiative to promote and disseminate quality educational research outcomes across the globe (20). This initiative was started out of the realization that there was no specific local journal to highlight research outputs and innovations produced by Malaysian researchers in the medical and allied 
health education field. Through a concerted effort by the department as well as through the networks available, the EIMJ was created and is now indexed in reputable databases such as EBSCOhost, MyCite, Google Scholar, Index Copernicus, Regional Information Centre for Science and Technology (RICeST), UDLTheses, Ulrichweb, and National Library of Malaysia. Continuous effort is taken by the department to ensure that the journal is indexed in other renowned databases such as PubMed, Scopus and ISI. Recently, the EIMJ has obtained an APEX incentive grant to upgrade the journal management system through a new server to ensure a smooth publication process. The journal is now accessible at www.eduimed.com that is specifically dedicated to the EIMJ. Further information about the EIMJ can be acquired from the journal website. Beginning from 2013, EIMJ publishes 4 issues per year to shorten the period of publication upon acceptance of articles and to increase likelihood of the journal being indexed in the renowned databases (21).

\subsection{Services and external services}

\subsection{Conducting faculty development to external clients}

Faculty development provided by the MED is not only confined to internal clients, but it also provided to external clients based on request. External clients included the Conjoint MMed Boards of Examination for Surgery, Family Medicine, Paediatrics and Psychiatry, various schools within USM such as the Advanced Medicine and Dental Institute (AMDI) and the Dental School; different institutions of higher learning such as UCSI, Taylor College, Perak Medical College UniKL and UNIZA, The department is planning to provide more external services through a structured external faculty development programme, which can also generate income for the school.

\subsection{International recognition for medical school excellence through the ASPIRE award}

In line with the current movement towards achieving external recognition for excellence in medical education, the department plans to put forward a proposal for the USM medical school to participate in the ASPIRE award headed by the Association of Medical Education for Europe (AMEE). This prestigious award was introduced in 2012 to recognize medical school excellence in three areas which are 1) student assessment, 2) student engagement in the curriculum and in the medical school, and 3) social responsibility and accountability as a mission of the medical school (22). Participation in the ASPIRE award will increase branding and image of the services provided by the USM medical school internationally. In the long-term, it may attract more international students to further their studies in the USM medical school and therefore will directly improve USM reputation internationally.

\subsection{Students and alumni}

\subsection{Facilitating student involvement in personal and professional development activities}

The MED plays an important role in facilitating student involvement in personal and professional development activities. Among the activities conducted by the department are the Discovering Potential for Sustainable Transformation (DPST) workshop series (23-27), The Postgraduate Personal and Professional Development Program (28-38), and the medical student wellbeing workshop (18). These activities are designed and conducted to help medical students realize their potential for self-improvement so that they will be able to deal effectively with the demanding and challenging medical training environment (39). All these efforts are aimed towards betterment of medical student wellbeing.

\subsection{Postgraduate studies}

\subsection{Customized Medical Education Program (c- MedEdu)}

The department is in the process of revamping its current Master of Science in Medical Education program into a more customized and step wise medical education program from a certificate up to master levels (c-MedEdu), making it more flexible, dynamic and attractive so that more candidates will be able to join the program in the future. One of the reasons for the proposed change in the program structure and process is 
the observation that every year the department receives many qualified applicants but the actual number of candidates registering remained small due to the inability of many candidates to fit into the program structure that requires at least a year of fulltime course commitment.

\subsection{International cross recognition of courses or work done towards a qualification (initiated by $A M E E$ )}

Apart from restructuring the Master program, MED is also involved in obtaining international cross recognition of its master program in medical and health profession education, in line towards an across-the-globe qualification (40). This ensures that candidates with a master degree in medical education from USM are recognized by other universities around the globe. This initiative will improve the employability of graduates from USM. This effort is still under process and hopefully will materialize soon.

\subsection{The concentration of talent}

\subsection{Medical Education Research and Innovation Unit (MERIU)}

MERIU was initiated as a specific unit to facilitate research and innovation activities in the department. This unit looks at the strengths and opportunities for the department members to engage with potential research and innovation activities, while on the other hand it is also looking at the weaknesses and threats that might be corrected, avoided, removed or improved upon to ensure the research and innovation activities flourish. This unit also hopes to stimulate more research and innovation activities at intra-department level so that potential research or innovation proposals could be put forward to the appropriate USM research platforms.

\subsection{Engaging in Medical Education Research (EMER) Program}

The EMER program was introduced with the aim to expose and engage medical teachers to various areas of research in medical education. Thus, it is hoped that more medical teachers will be interested to do research in medical education. Likewise this program would be able to identify medical teachers with interest in doing research in medical education so that they could be pooled into appropriate special-interest groups. These groups can then produce and present proposals to the MED for comments and suggestions for improvement. High impact and good quality proposals would then be recommended for research grant application. This effort will assemble medical teachers from various medical specialties to sit together to think on action research that may improve the teaching and learning environment in the medical school.

\subsection{Resources}

\subsection{Smart-partnership approaches}

Dealing with students as well as faculty members is a challenging task for the MED members because it requires a lot of resources particularly time and human resource. One way of optimizing and maximizing available resources is a smart-partnership approach with various stakeholders. A few examples of the smartpartnership approaches are the appointment of associated medical education members as connectors to other departments, the BigSib program as connectors to medical students and the Medical Student Facilitator Team as connectors to the community or society. This approach enables the department to synergize all the available resources for the utmost benefits to students, faculty members and community. We hope that these smart-partnership approaches will benefit the bottom billions as championed by USM (1).

\subsection{Supportive governance}

Apart from the roles and initiatives described previously, the MED plays an important role in supporting the governance of the USM medical school. Among the supportive roles played by the departments are 1) assisting the medical school in student selection, 2) sitting in and participating at the central vetting committee for all Professional Examinations at both the undergraduate and post graduate levels, 3) providing detailed item analysis feedback on the performance of the summative assessments for 
Phase 1, 2 and 3 with regards to their reliability and validity, 4) preparing medical teachers, administrative staff and students for curriculum reviews, 5) planning and conducting orientation programs for new medical teachers as well as medical students, and 6) providing the best evidence in medical education to faculty members for continuous program evaluation and improvement (3).

\subsection{Summary}

In a nutshell, the Medical Education Department has put in a concerted effort to; 1) eliminate or reduce the gaps in resources, bureaucracy in governance and talent mismatch; 2) raise activities to meet global agenda, increase autonomy and accountability of students and faculty members to develop relevant skills, improve the quality of services through continuous evaluation and improvement, and emphasizing on matters relevant for future educational impacts; and 3) create a local solution to promote scholarship of and scholarly teaching activities through publication in the EIMJ and OPREMA, and introducing the smartpartnership approaches to synergize available resources so that a sustainable positive impact could be produced for the benefit of the bottom billions.

\section{Reference}

1. Dzulkifli AR, Ramli M. Transforming Higher Edication for A Sustainable Tommorrow. Pulau Pinang, Malaysia: Universiti Sains Malaysia; 2008.

2. Harden RM, Crosby J. AMEE Guide no 20: The good teacher is more than a lecturer the twelve roles of the teacher. Medical Teacher. 2000;22(4):334-47.

3. Rogayah J. Two decades of championing faculty development: Is it worth the effort? Education in Medicine Journal. 2012;4(2):e1-6.

4. Wilkerson LA, David M. Strategies for improving teaching practice: A comprehensive approach to faculty development. Academic Medicine. 1998;7(3):387-96.

5. Jason H, Westberg J. Teachers and teaching in US medical schools. United State America: Appleton-Century-Crofts; 1982.
6. Steinert Y, Cruess S, Cruess R, Snell L. Faculty development for teaching and evaluating professionalism: from programme design to curriculum change. Medical Education. 2005;39(2):127-36.

7. Astin AW. Student involvement: A developmental theory for higher education. Journal of college student personnel. 1984;25(4):297-308.

8. Yusoff MSB, Abdul Rahim AF, Rahman Noor A, Yaacob NA, Mohd Hussin ZA. Evaluation of medical students' perception towards the BigSib Programme in the School of Medical Sciences, USM. Education in Medicine Journal. 2010;2(1):e2-11.

9. Yusoff MSB, Rahim AFA, Noor AR, Yaacob NA, Hussin ZAM. The BigSib students' peer group mentoring programme. Medical Education. 2009;43(11):1106-.

10. Yusoff M, Rahim A. The Study Skills Workshop. MedEdPORTAL; 2010.

11. Abdul Rahim AF. Guide for assessment in phase 1. Malaysia: KKMED Publications; 2010.

12. Abdul Rahim AF, Hafiza A. PBL in PPSP: A guide for students. Malaysia: KKMED Publications; 2010.

13. Richlin L. Scholarly teaching and the scholarship of teaching. New directions for teaching and learning. 2001;2001(86):57-68.

14. Yusoff MSB. Publishing Teaching Materials Workshop: Experience of USM Medical School. Education in Medicine Journal. 2012;4(1):e144.

15. Candler C, Hafler J, Simpson D, Chauvin S, Souza K, Nowacek G. Educational Scholarship Guides. MedEdPORTAL. 2009.

16. Yusoff MSB. Disrepancy-agreement grading provides feedback on rater judgments. Medical Education. 2012;46(11):1122.

17. Yusoff MSB, Abdul Rahim AF. The discrepancy-agreement grade (DAG): a novel grading system to provide feedback on rater judgments. Education in Medicine Journal. 2012;4(2):e100-4.

18. Yusoff MSB, Esa AR. The Medical Student Wellbeing MedEdPORTAL2012.

19. Azman MA-z, Yaacob NA, Yusoff MSB, Noor SH. Comparative Study on Medical Student Personality Traits between Interview and Non-interview Admission Method in University Sains Malaysia. Procedia-Social and Behavioral Sciences. 2014;116:2281-5.

20. Yusoff MSB, Abdul Rahim AF. Welcome to the Education in Medicine Journal. 
Education in Medicine Journal. 2010;2(1):e1.

21. Yusoff MSB. Visibility of Education in Medicine Journal. Education in Medicine Journal. 2014;6(1):e1-e2.

22. AMEE. ASPIRE - A Medical Schools Programme for International Recognition of Excellence in Education. UK: AMEE; 2012 [14 November 2012]; Available from: http://www.amee.org/index.asp?tm=66.

23. Yusoff MSB, Abdul Rahim AF, Yaacob NA. Maximising your personality. Malaysia: KKMED Publications; 2010.

24. Yusoff MSB, Abdul Rahim AF, Yaacob NA. Leading to lead. Malaysia: KKMED Publications; 2010.

25. Yusoff MSB, Abdul Rahim AF, Yaacob NA. Taming your enemy. Malaysia: KKMED Publications; 2010.

26. Yusoff MSB, Abdul Rahim AF, Yaacob NA. Responding to change. Malaysia: KKMED Publications; 2010.

27. Sheikh Hamzah M, Mat Pa MN, Sepehr S. Interfacing strategies. Malaysia: KKMED Publications; 2010.

28. Rogayah J, Mohd Hussin ZA, Yaacob NA, Yusoff MSB. Personal \& Profession Development Programme for Posgraduate Volume 5: Nurturing \& Working Through Leadership \& Ethics. Malaysia: Pustaka Aman Press; 2009.

29. Rogayah J, Esa AR, Ibrahim MI, Yusoff MSB. Personal \& Professional Development Programme for Postgraduate Volume 4: Management \& Organization Skills for Postgraduate. Malaysia: Pustaka Aman Press; 2009.

30. Abdul Rahim AF. Personal \& Professional Development Programme for Postgraduate Volume 3: Specialist as a Counselor. Malaysia: Pustaka Aman Press; 2009.

31. Yusoff MSB. Personal \& Professional Development Programme for Postgraduate Volume 2: Nurturing \& Working with Emotional Intelligence (EQ). Malaysia: Pustaka Aman Press; 2009.

32. Yusoff MSB. Personal \& Professional Development Programme for Postgraduate Volume 1: Exploring \& Managing Stress. Malaysia: Pustaka Aman Press; 2009.

33. Yusoff MSB, Rahim AFA. The Postgraduate Personal and Professional Development Programme. Education in Medicine Journal. 2010;2(1):e35.

34. Yusoff MSB, Ja'afar R, Yaacob NA, Mohd Hussin ZA. Leadership and Ethics Workshop for Postgraduate Students.
Education in Medicine Journal. 2009;1(1):e1.

35. Yusoff MSB, Ja'afar R, Esa AR, Ibrahim MI, Abraham M. Management and Organizational Skills Workshop for Postgraduate Students. Education in Medicine Journal. 2009;1(1):e1.

36. Yusoff MSB. Nurturing and Working with Emotional Quotient (EQ) Workshop. Education in Medicine Journal. 2009;1(1):e1.

37. Yusoff MSB. The Postgraduate Exploring and Managing Stress Workshop. Education in Medicine Journal. 2009;1(1):e1.

38. Rahim FAR, Yusoff MSB. Experience from a Workshop on Counseling Skills for Postgraduate Students. Education in Medicine Journal. 2009;1(1):e1.

39. Yusoff MSB, Abdul Rahim AF, Baba AA, Ismail SB, Mat Pa MN, Esa AR. The impact of medical education on psychological health of students: A cohort study. Psychology, Health \& Medicine. 2012.

40. Tekian A, Harris I. Preparing health professions education leaders worldwide: A description of masters-level programs. Medical Teacher. 2012;34(1):52-8. 